\title{
COMPARISON OF RECORDS OF BALEEN PLATES AND OF EAR PLUGS IN FEMALE FIN WHALES, BALAENOPTERA PHYSALUS (LINNAEUS, 1758)
}

\author{
by \\ W. L. VAN UTRECHT \& C. N. VAN UTRECHT-COCK \\ Zoological Laboratory, University of Amsterdam
}

\section{INTRODUCTION}

Purves (1955, 1958), Laws and Purves (1956) and Purves and Mountford (1959) have given extensive descriptions of the presence of alternating light and dark layers in the ear plugs of baleen whales. Their assumption that these layers are seasonal depositions is based on the regular sequence of a feeding season and a non feeding season with migratory movements in between. They have also counted the number of layers visible in the core of the ear plug and correlated these with data about the body length of e.g. the fin whales at sexual and physical maturity. Their conclusion was that there is a relation between the number of layers present in the ear plug and the body length at which the animals attain sexual and physical maturity, and that the ear plug is useful in age determination. It was supposed that the advantage of the use of the ear plug over the use of the baleen plate in age determination is that the ear plugs are completely enclosed in the external meatus and in this way protected from wear and other influences which could cause loss of material from the ear plug. Therefore it was supposed that all material and all layers deposited during the life of the animal remained present unchanged and, therefore, better could be used in age readings than other criteria.

The baleen plates, which were shown to have value in age determination (Ruud, 1940, 1945, 1958; Van Utrecht, 1966 and Van Utrecht-Cock, 1966), are indeed subject to wear at the tip, so that part of the baleen plate is always missing in animals above a certain age (as a mean about 5 years). A correction, however, is possible with the help of the corpora albicantia, the signs of ovulations, which remain visible in the ovaries of baleen whales during their life. It has to be presumed that the combined results of age determination by means of an analysis of the baleen plates and of the ovaries must give the same results as those derived from the analysis of the ear plugs.

As a result of various investigations it was supposed that the accumulation rate of the layers in the ear plug is two per annum. This is mainly based on the assumption of a more or less regular sequence of migration, feeding season, migration, non feeding season or reproduction season, migration, etc. However, as data from whale marking and age determination and about the sexual cycle were accumulating, doubt arose and discussion started on the yearly rate of increment of the layers in the ear plug.

Ohsumi (1964) counted the number of layers of 6 fin whales caught 25 years after marking. The numbers of laminae were: $38,38,33,28,36,34$. This would point to a mean rate of accumulation of 1.52 layers per year.

These results gave an extra impulse to the discussion. However, in our opinion these figures can also be accounted for when it is assumed that the rate of accumulation is greater than two layers per year. Then the layers at the distal end of the core of the plugs are pressed together to form a mass in which the layers are poorly or not at all to be discriminated. Indeed we do not really know the rate of growth of the ear plug. This is also true of the mean maximum number of layers that may be visible in the ear plug. All countings of the layers in the core of the ear plug have been done by the naked eye. No special apparatus or methods are used. This accounts for the results being very variable and evidently subjective. This clearly appears from the results of countings by a number of experienced people, as laid down in a report presented at the meeting of the International Whaling Commission of July 1967. These results are a clear demonstration of the very limited value of the counting method. This conclusion is supported by Ichihara $(1963,1966)$, who studied the development, 
formation and growth of the ear plug (Ichihara, 1959, $1963,1964,1966)$ of fin whales and developed a method for recording the variations in light reflected by the polished surface of bisected ear plugs (Ichihara, 1963).

Roe (1967a) also studied the development and growth of the ear plug. Ichihara and Roe have shown that the core of the ear plug, in which the dark and light layers are present, is formed by the epidermis covering the meatal surface of the glove finger. They also analyzed the process of formation of the light and dark layers respectively. They found that a light layer consists of cells showing signs of fatty degeneration and having a high content of intercellular fat, while a dark layer originates from fusiform cells which show signs of keratinisation and have a very low content of intercellular fat.

Ichihara and Roe suppose a possible correlation between the feeding season during summer with the deposition of a light band and the occurrence of a dark band with the non feeding and reproduction season. Ichihara (1966) in particular tries to relate the occurrence of the light layer with a period of low mitotic activity in the epidermal tissue covering the glove finger and with inhibition of keratinisation by the high dose of vitamin A taken in with the food. The dark layer, in his opinion, can be ascribed to a period when the uptake of food is small and thus also the amount of vitamin A. On the other hand factors stimulating mitosis would influence the growth of the epithelium because there then is no inhibition of keratinisation. Both, Ichihara (1966) and Roe (1967), agree that the light layer is mainly formed in the feeding season. As a basis for their argumentation they use the regular sequence of a feeding season, migration, non feeding season, migration, etc. and calculate the annual increment of the layers in the ear plug. It is clear that in this way the annual increment must be about one light and about one dark layer per annum. They also have given graphs in which the relation of the mean percentages of light and dark layers per month are given. From Roe's graphs it is clear, however, that in all months of the year light and dark layers are formed though the mean percentages vary considerably.

However, considering the graph for mature females the numbers of individuals per month are very small. This is also true for the other groups of fin whales. In our opinion the numbers of animals are too small to lend much support to the supposition that two layers, a dark one and a light one, are formed per year.' Moreover, the graph for the mature females shows that always, even in the summer months, in
$10 \%$ of the animals or even more a dark layer is formed.

As the rate of growth of the ear plug is unknown these figures, in our opinion, do not necessarily indicate that one light and one dark layer are formed per year, and they could also be used for explaining a much higher rate of accumulation of the dark and light layers even twice as high or more.

Ruud (1940, 1945, 1958) has developed a method of age determination on baleen plates. His analysis of the baleen records is based also on the regular sequence of a feeding season - non feeding season, etc. Ruud supposes that, due to the sudden start of feeding in spring after a period of migration from lower latitudes to higher latitudes, the baleen plates also start to grow at a higher speed. This will result in a sudden increase in thickness. However, not in all baleen records these "jumps" are present and the distance between consecutive "jumps" is not very regular.

This is not surprising if the results of monthly observations on the occurrence of whales (Slijper, Van Utrecht and Naaktgeboren, 1964) are considered. One of the main results has been that the whales do not migrate as regularly as was formerly supposed and that in all months of the year Rorquals are to be found in lower latitudes. This is particularly evident in the Indian Ocean. Animals sighted in low latitudes, between $10^{\circ} \mathrm{N}$ and $20^{\circ} \mathrm{N}$, have mostly been found in areas which are relatively rich in food. So the possibility exists that they here take food, although no direct observations of feeding or on stomach contents are available. Direct observations of stomach contents are only known from baleen whales taken by catchers from the Durban whaling station. These whales are taken in the sea area around $30^{\circ} \mathrm{S}$, during their migratory movements to the north in the autumn and to the south in spring. It has been shown that the animals take small amounts of food when this is available (Bannister and Baker, 1967). Dawbin (1956) arrived at the same conclusion for the humpback whales migrating along the coast of New Zealand. These observations really do not support the idea which supposed that fin whales meet with two totally different circumstances during the year, a feeding season and a non feeding season. The same is true for reproduction. Naaktgeboren, Slijper and Van Utrecht (1960) have shown that there are two peaks in the main growth curve of the foetuses of fin whales. This means that there are two periods during which the greater number of births occur. These periods are March to May and September to November. This also means that there are two main periods 
of conception. In other words it is reasonable to expect female fin whales which have recently ovulated, in nearly all months of the year. So it is evident that a clearly defined feeding season and an equally well defined reproduction season do not exist.

In further research on the growth of the baleen plate (Van Utrecht, 1966) it was shown that extra depositions of cornifying cell material, which form the very first beginning of the cortex in the "root" of the baleen plate are momentary depositions resulting from increased mitotic activity in the epidermal tissue of the gum by which the cortical layer of the baleen plate is formed. Nowhere else than only at the very first beginning of the cortical layer cell material from the gum is added to this layer. This also means that the total thickness of the baleen plate is already determined at the basis of its "root", also because the addition is symmetrical to both sides of the plate.

In the analysis of the records of thickness of the baleen plates of fin whales (Van Utrecht-Cock, 1966) the record of the course of the thickness of the "root" part of the plate embedded in the gum is also used. So the entire length of the baleen plate from the point where it is formed to its tip has been used. This thus is comparable to what is done for the ear plugs.

From the analysis of the records of baleen plates of female fin whales it became evident that certain peaks and combinations of peaks were very pronounced and occurred at irregular intervals as well in the curve of the thickness of the "root" of the plate as also in the free baleen plate. It was shown that in the case of a pregnant female such a peak or combination of peaks were present in the record pertaining to the "root" of the baleen plate. The distance of this peak to the beginning of the cortex ("date point" i.e. the moment the animals died) corresponds with the length of the foetus on the basis of growth curves (Laws, 1961; Naaktgeboren, Slijper and Van Utrecht, 1960). The distance between two such peaks or combinations of peaks also corresponds with a complete pregnancy and lactation period at least, calculated on the basis of the speed of growth of the foetus. This made it evident that these pronounced peaks are related to or caused by an ovulation and it was supposed that the mitotic activity in the epidermal tissue of the gum was raised by the increased production of oestrogen immediately prior to or at the moment of ovulation (see Bullough, 1943, 1947; Bullough, 1946, 1962). In this way more material is added from the gum to form the cortex than is normally the case when the mitotic activity is at a lower level. From the baleen records it is of course clear that also other factors can stimulate or retard the growth of the baleen plate. Moreover in the records a difference in pattern is clearly present when comparing those of male and of female fin whales. In the records of baleen plates of males the pattern is more regular. In our opinion the irregularity in the records of females is due to the sexual cycle which can show great variations in length of time, as a pregnancy and lactation period lasts about 18 months, while the interval between two ovulations without pregnancy can last about four to six months.

From the baleen records of males we got the impression that the maximum duration of the period of sexual activity is about four to six months in regular sequence with an inactive period, in this respect, during the summer months.

From our investigation of baleen plates it has become evident that the sexual cycle, by its stimulating influence on the epidermal tissue involved in the formation of the baleen plate, influences the growth of the plate, which is particularly demonstrated in a sudden increase in thickness resulting in a peak. Ichihara (1966), Rice and Wolman (1967) and Roe (1967a) also mention that there is a greater regularity in the sequence of light and dark layers in the ear plugs of male Rorquals than there is in the ear plugs of females. This points to an influence of the sexual cycle on the growth of the ear plug. It is also shown that the part of the baleen plate embedded in the gum is very important in the analysis because this provides the "date point" in the part of the plate which was last formed. Beside these facts it could be demonstrated that there is a certain sequence in peaks and hollows in the record of the baleen plate, typical for each individual fin whale, which is regularly repeated along the entire length of the record. This regular repetition made it possible to divide the record into "growth periods". As far as could be ascertained these "growth periods" cover a period of about 12 months (see Van Utrecht-Cock, 1966).

Baleen plates and ear plugs are formed by epidermal tissue. It is reasonable to assume that when the rate of mitosis increases in the epithelium which forms the baleen plate, the mitotic activity in the epithelium which forms the ear plug, also increases. So it is to be expected that certain features made visible in the records of baleen plates in some form or other must also be present in the ear plug.

Our objection against counting the laminations in ear plugs is that it is overlooked that these laminations represent momentary depositions due to changes in the mitotic activity of the epithelium caused by a great variety of influences. For the baleen plates it 
is demonstrated that one of these influences is the oestrogen production due to an ovulation.

From our research on baleen plates (Van Utrecht, 1966; Van Utrecht-Cock, 1966) it is clear that it has no sense to count the peaks present in a baleen record, because the individual peaks, those caused by an ovulation inclusive, have no direct relation to the age of the animal. Only the combination of peaks in a regular cyclic repetition are useful in age determination. It is reasonable to assume that this condition for age determination on baleen plates is also valid for the analysis of the ear plugs or records of them. Based on this assumption the records of baleen plates and ear plugs are compared and analysed.

\section{MATERIAL AND METHOD}

The material used in this research consists of ear plugs, baleen plates including the parts of the plates embedded in the gum, and ovaries from 54 female fin whales. All ear plugs used were complete and undamaged. Of these animals four were sexually immature individuals and 50 were sexually mature. The material was collected on board the former Dutch f.f. "Willem Barendsz" during the Antarctic whaling season 1962-1963.

Concerning these animals the following data are available: date of catch, registration number, sex, length of the animal, presence or absence of a foetus, number of foetuses, length of the foetus(es), sex of the foetus(es), position of catch, and diagnosis of the Whaling Inspectors concerning the condition of the mammary glands.

Baleen records are made and analysed according to the method described by Van Utrecht-Cock (1966). For the baleen plates the number of "growth periods" is given for the total baleen plate (outer baleen plate + part of the plate embedded in the gum), the length of the "growth periods" is given for the outer baleen plates only. The records of the core of the ear plugs have been obtained according to the principles described by Ichihara (1963, 1966), although the method had to be modified and adapted to the apparatus available. In his method the amount of light reflected by the polished surface of the ear plug is measured and recorded. The following set of apparatus was used (fig. 1): a Leitz Laborlux microscope of which the mounting table was replaced by an endless conveyor belt driven by a variable speed motor. From the optics only an objective lens is used. Instead of the ocular we used a Leitz foto multiplier, type M.P.E. to which an optical device is attached by which temporary visual control is possible. Further were used a Vitatron 220 Volts DC stabilizer,

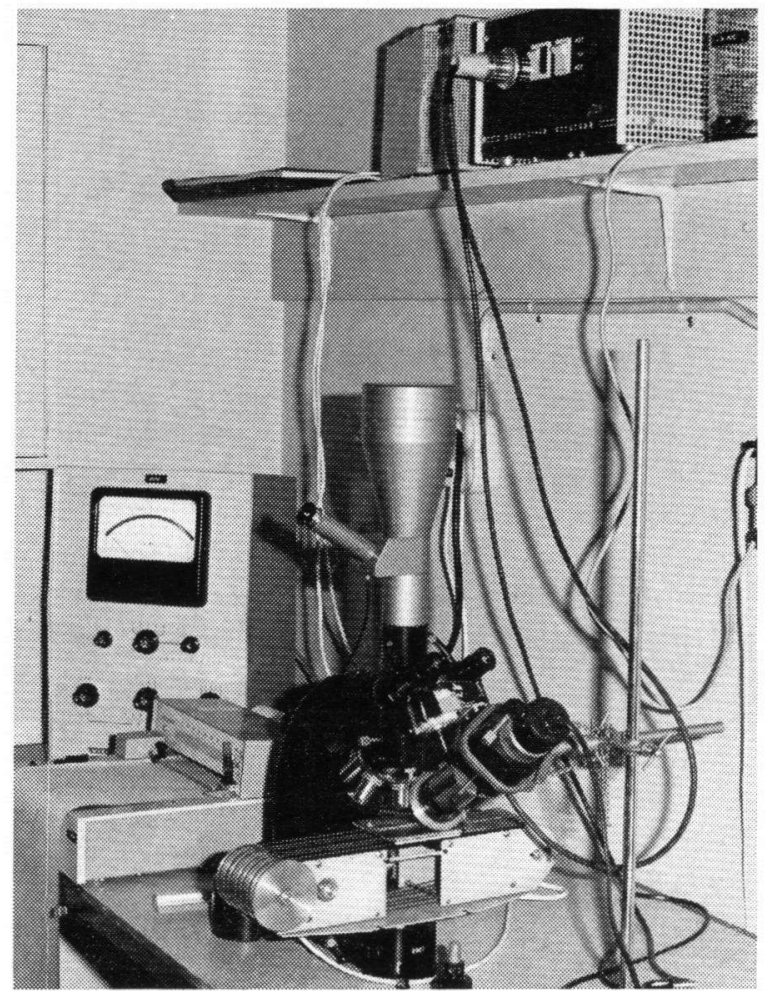

Fig. 1. Photometric apparatus to make records of ear plugs.

a Vitatron signal amplifier and a Vitatron strip chart recorder. The motor of the belt, the amplifier and recorder are fed by the stabilizer. The bisected ear plug was mounted on the conveyor belt. The polished surface was wetted with distilled water and a large microscope cover glass put on it. The surface of the plug was illuminated by an incandescent lamp fed by 220 Volts DC stabilizer. By means of optics a parallel bundle of light was formed, which was directed at the surface of the plug, under an angle of $45^{\circ}$. The bundle of light was interrupted by a chopper at 50 periods/sec. exactly. The motor of the chopper was also fed by 220 Volts DC. This chopper is needed to generate an alternating current in the photo multiplier. The signal of the photo multiplier was fed into the Vitatron alternating current amplifier. The amplifier signal was fed into the recorder. The speed of the ear plug and the paper of the recorder was equal and constant. The magnification by the optical system used was 8.5 times. With this set of apparatus the changes in amount of light reflected by the polished surface are determined as the plug passes underneath the objective and recorded as a curve on a strip of paper. In fact the brightness of the surface of the bisected ear plug is measured and therefore the peaks correspond with the light bands 
in the core of the plugs. This also means that our records are comparable with the records published by Ichihara (1966). The weights of the ovaries and the weights and measurements of the corpora were determined according to the methods described by Van Utrecht-Cock (1966).

The authors are very grateful to the Board of Directors of the former Netherlands Whaling Company Ltd. and the officers and crew serving on board the former f.f. "Willem Barendsz" for their cooperation. They are very grateful to Mr. W. H. E. van Dijk, formerly Chief Whaling Inspector who did most of the work in carefully collecting the material and data, and to Prof. Dr H. Engel for his critical reading the manuscript. The authors wish also to thank Drs. P. C. Diegenbach who was so kind to give the advises concerning the apparatus used to produce the records of the ear plug and to Miss E. M. de Graaf for her technical assistance.

\section{RESULTS}

The most important condition for valuable comparison of baleen records with ear plug records is that both must start at corresponding points. The parts of both records representing the distal end of the baleen plate and of the ear plug can not be used because of the wearing off of an unknown part of the baleen plate. Moreover it seems very real to suppose that part of the material of the ear plug at its distal end has been compressed. Ichihara (1966) started the comparison of the record of the ear plug with the record of the baleen plate at the point where the baleen plate is out of the gum, while for the ear plug he used the complete record, from the part last formed at the epithelium up to the tip of the plug. So he started the comparison at points not corresponding with each other in time and age. For this comparison Ichihara reduced the length of the baleen record to a length equal to that of the record of the ear plug. In this way many details in the baleen record are lost and therefore this record is no longer comparable to the curve of the ear plug. The only points in the record of the baleen plate and the record of the ear plug which correspond with each other, are in both cases the parts last formed. Therefore it is very important also to use the part of the baleen plate embedded in the gum.

In general, the records of the ear plugs made according to the method described on p. 83 are of the same character as the baleen records and show a high degree of similarity with these records. This similarity is particularly clear when the record of an ear plug of a fin whale is compared with the baleen records of the same animal (see figs. 2, 3, 4). The succession of the peaks and hollows in the record of the ear plug is identical with their succession in the baleen record as is also the general trend in both records. The combination of peaks, which are typical for a particular baleen plate are also present and identical with those in the record of the ear plug in a certain individual.

The resemblance of the record of the ear plug to that of the baleen plate of one individual fin whale is striking.

As both, the baleen plate and the ear plug, are formed by epidermal tissue, it is reasonable to assume that both epithelia will react identically on e.g. a stimulans or sequence of stimuli, which thus will result in corresponding depositions in the baleen plate and in the ear plug.

As is said on page 82 it is possible to divide the baleen record into "growth periods", in each of which there is a repetition of the sequence and height of peaks and hollows (see also Van Utrecht-Cock, 1966). This is also done for the baleen records of the female fin whales used here.

In the same way the records of the ear plugs are divided into "growth periods". The division lines between the periods in the record could only be placed at points comparable to those in the baleen record. Comparing the records of the ear plugs we find a repetition of the sequence and height of the peaks and hollows, which is the same as in the baleen record, although on a much smaller scale (fig. 2). This points to a lower speed of growth of the ear plug than for the baleen plate.

In the records of baleen plates of two young animals the "double hump", generally related with sucking and weaning, is present. In the record of the ear plug of these animals there is also a "double hump", which in each individual was completely comparable to the "double hump" in the baleen record (fig. 3).

In the records of ear plugs of older female fin whales, a number of typical peaks were present. In the records of the corresponding baleen plates the same peaks were present, relatively in the same position as compared with the peaks and hollows on either side. In fig. 4 records are given of a female which has just become sexually mature, and has ovulated and is pregnant for the first time.

The material used for the comparison of baleen records and records of ear plugs was that of 54 female fin whales caught in Antarctic waters. These were chosen at random from a large sample. The data and material of four animals were excluded because the 
Fig. 2. (a-e). Records of baleen plates and ear plugs of fine whales. I. Record outer baleen plate. II. Record of part of the baleen plate embedded in the gum. III. Record of the ear plug. 1: "date point".

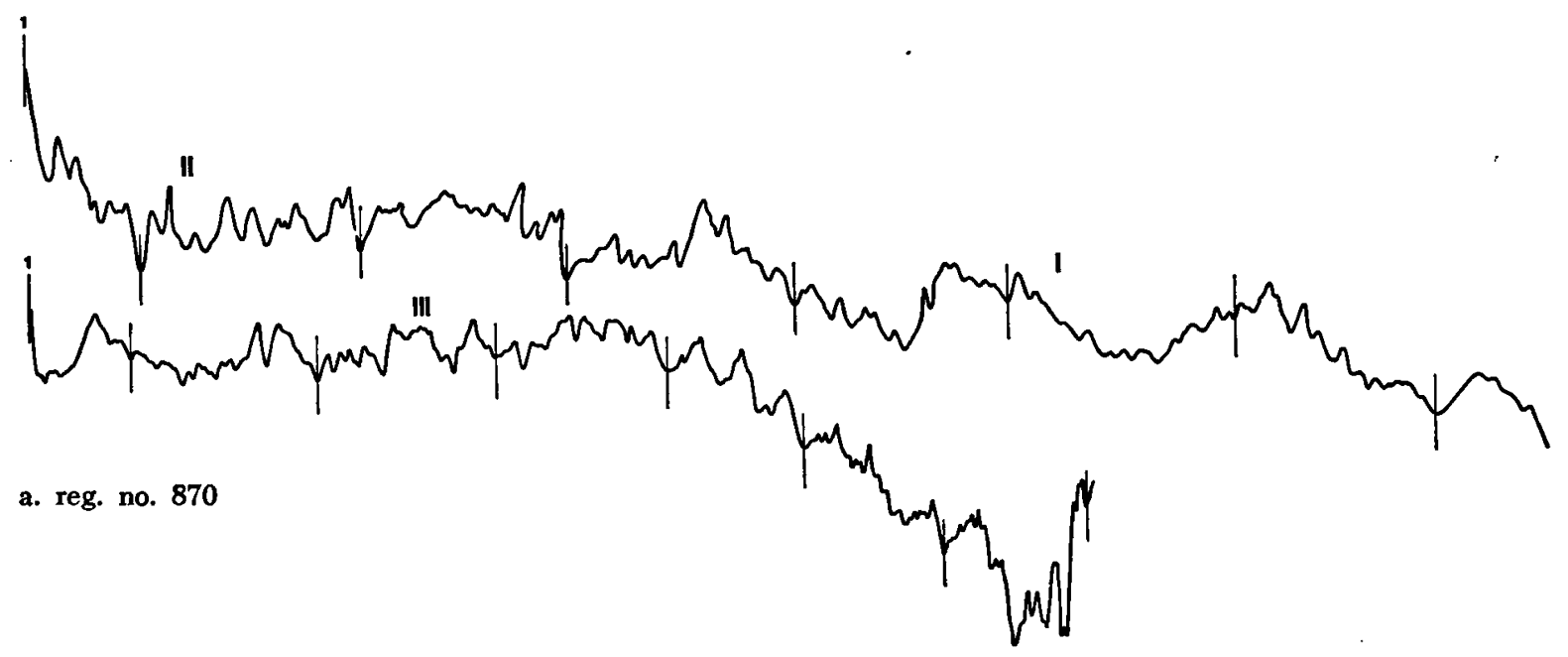

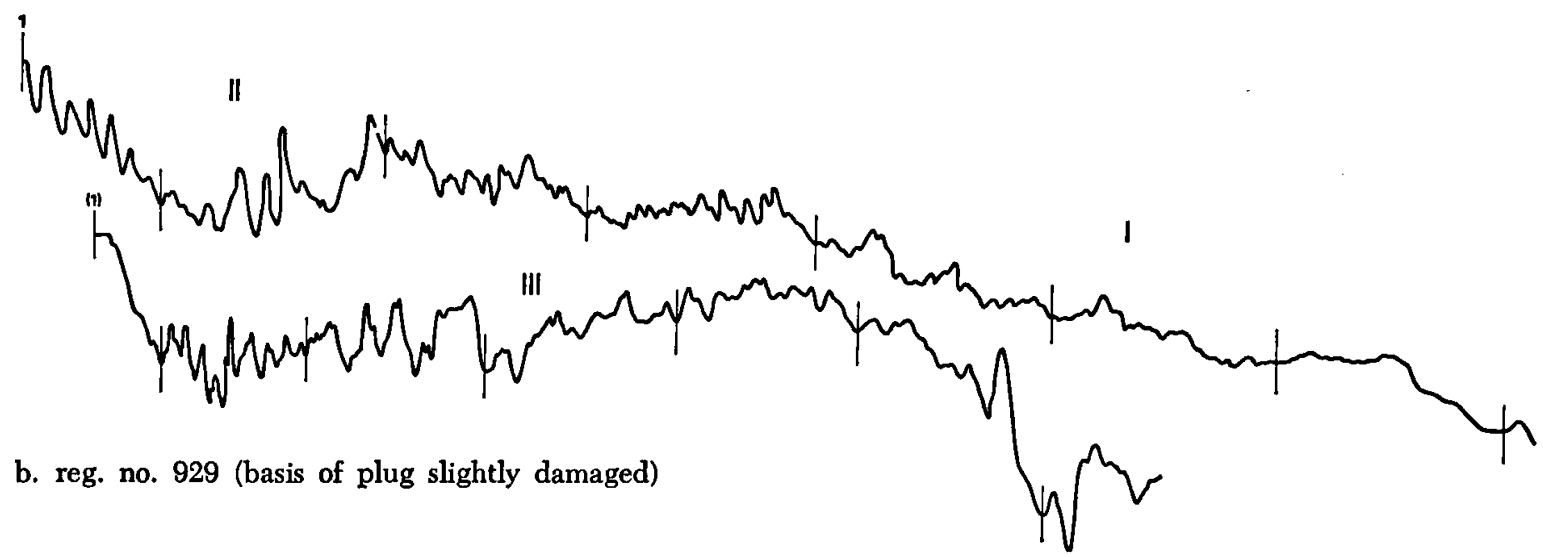

in

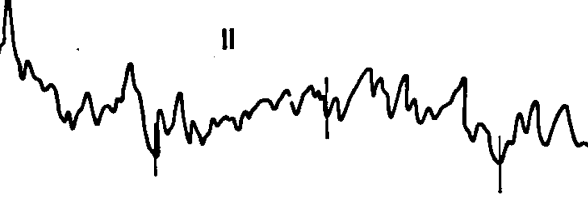

c. reg. no. 824

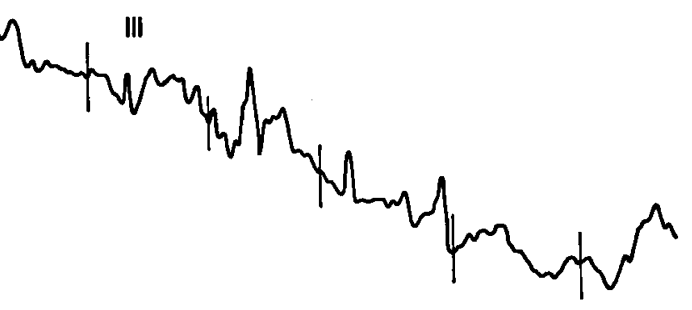




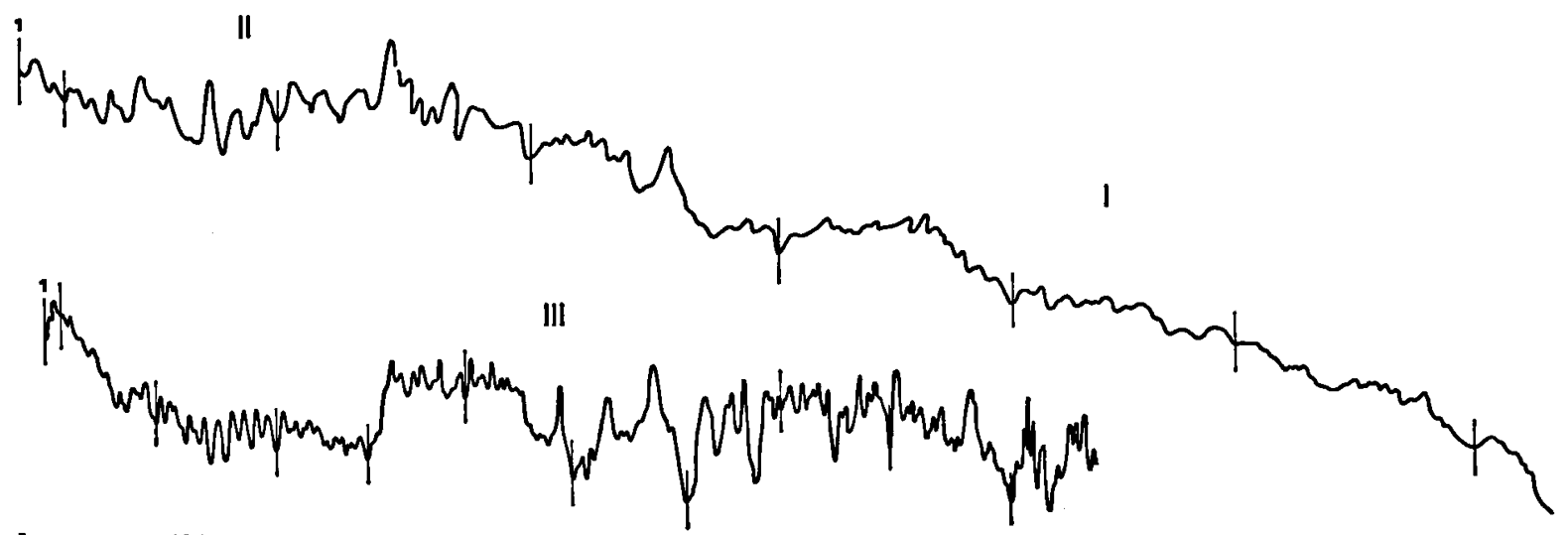

d. reg. no. 480

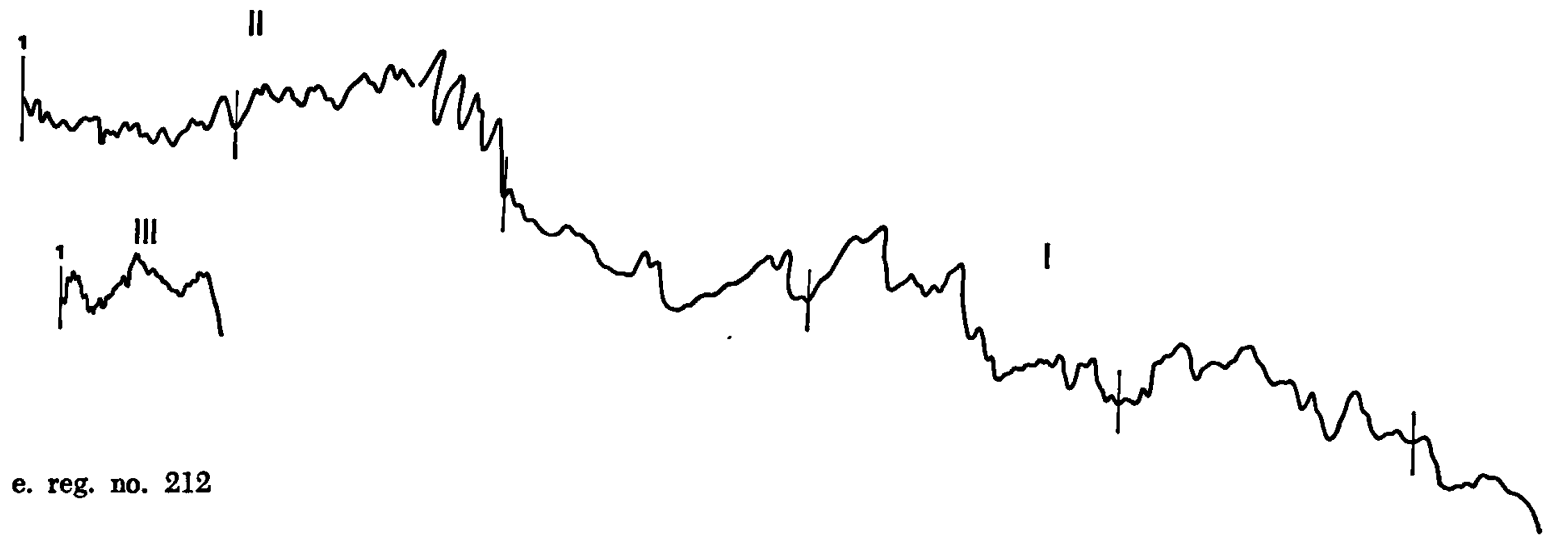

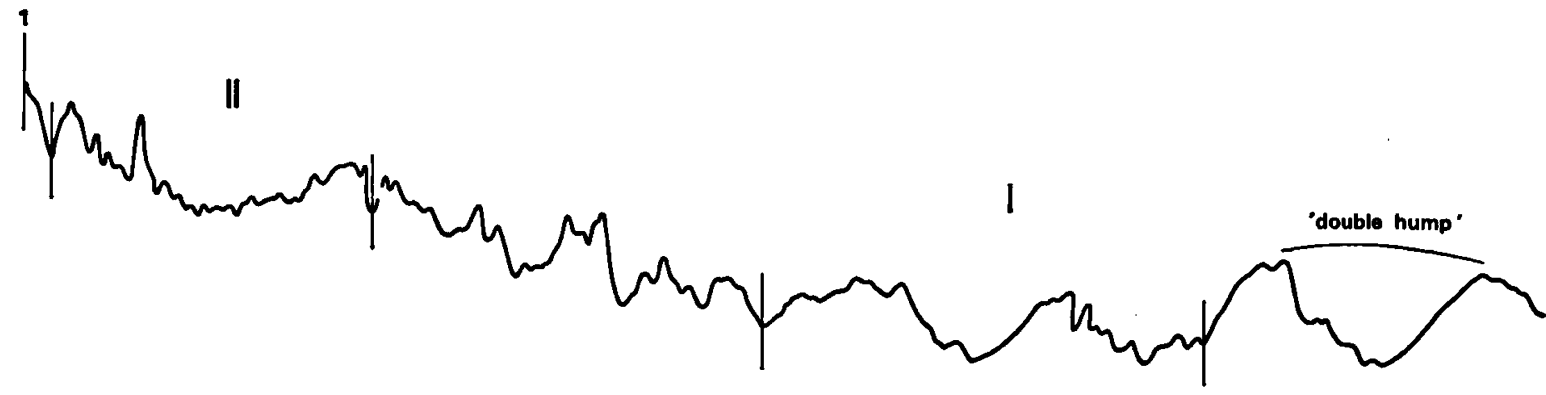

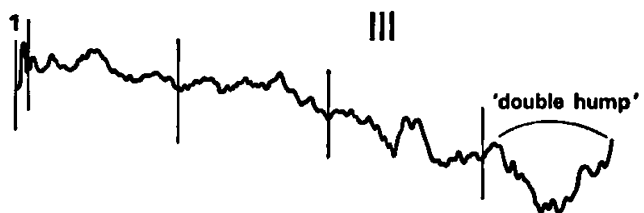

Fig. 3. Records of baleen plate and ear plug of fin whale, reg. no. 818, with "double hump". I. Record outer baleen plate. II. Record of part of the baleen plate embedded in the gum. III. Record of the ear plug. 1: "date point". 


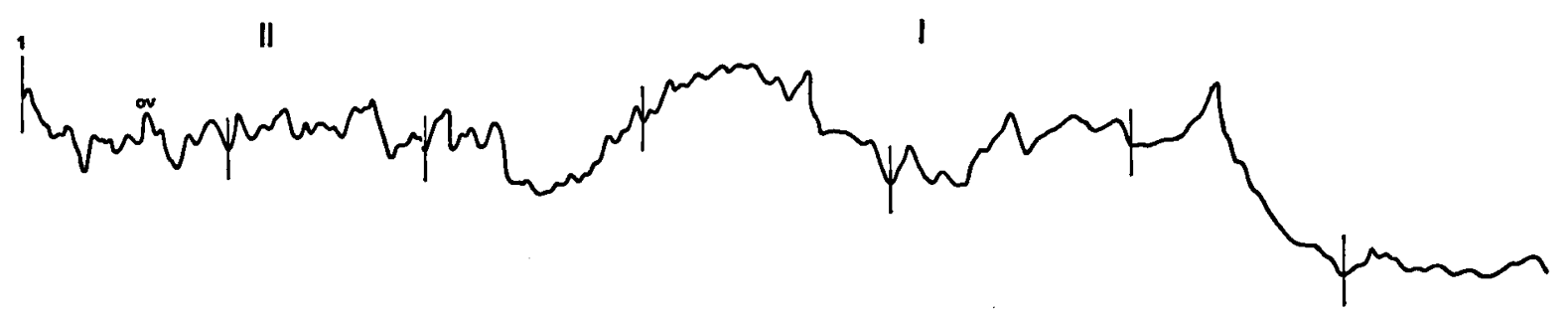

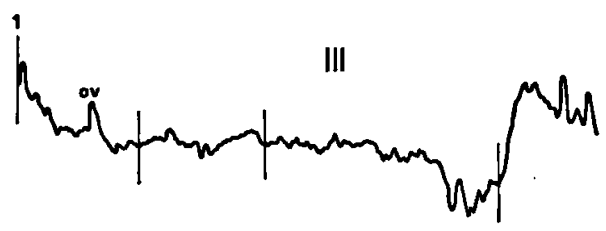

Fig. 4. Records of baleen plate and ear plug of fin whale reg. no. 378, with an "ovulation peak". I. Record outer baleen plate. II. Record of part of the baleen plate embedded in the gum. III. Record of the ear plug. 1: "date point". o.v.: "ovulation peak".

ear plugs of these animals proved to be badly damaged.

Of 50 animals the following details are important to show that all age groups are present, though each in very small numbers (table I).

\section{A. LENGth OF the BaleEN PLATE AND OF THE EAR PLUG}

Van Utrecht-Cock (1966) has shown that there is a relation between the length of the animal and the length of the baleen plate. These calculations have also been made for the material used in this comparison.

The relation of the length of the animal with the length of the baleen plate as shown formerly, is for this material $y=0.95 x-0.51(x=$ length of the animal in feet, $y=$ length of the baleen plate in $\mathrm{cm}$ ). The best fitting straight line differs significantly from the horizontal line as is proved by Student's t-test $(v=50, t=6.05, \mathrm{P}<0.05$ ) (fig. 5).

The length of the ear plug measured in a straight line along the record of the ear plug, which has a linear enlargement of 8.5 times, shows the same relation as was found for the baleen plates $(y=1.43 x$ $-64.50 ; x=$ length of the animal in feet, $y=$ length of the ear plug in $\mathrm{cm})$. The best fitting straight line differs also significantly from the horizontal line $(\nu=$ $50, t=3.39, \mathrm{P}<0.05$ ) (fig. 6 ).

From these calculations it was concluded that generally longer animals have longer baleen plates and ear plugs than shorter animals. In the baleen plates and ear plugs there is a similar relation be-
Table I

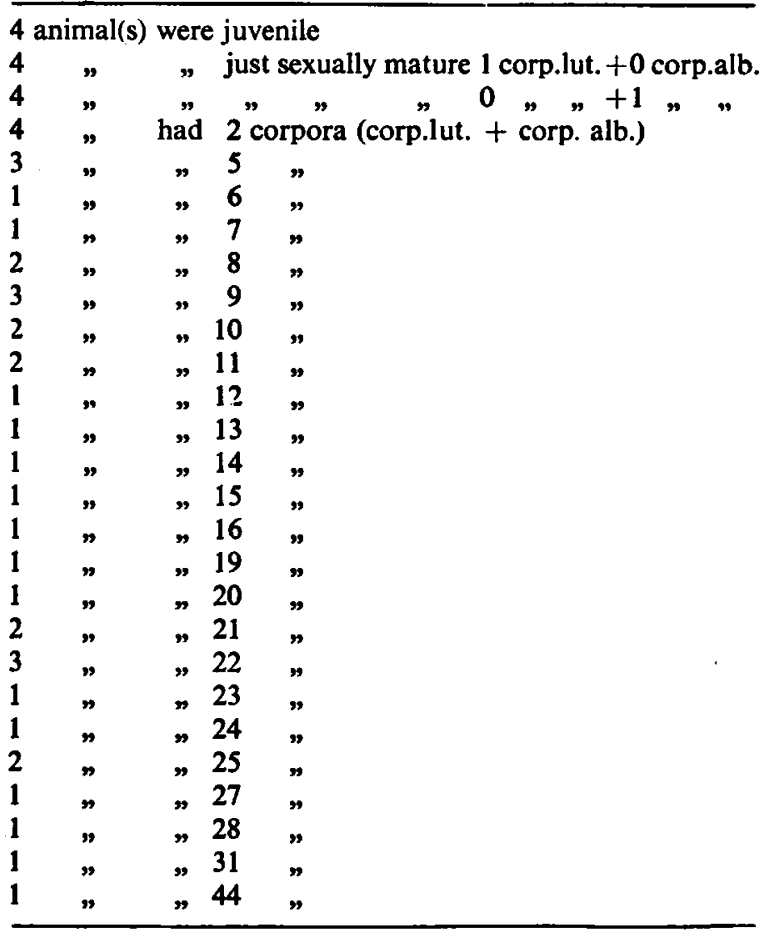

tween the length of the baleen plates and ear plugs and the number of "growth periods". On an average a greater number of periods was found in longer baleen plates and ear plugs.

The equation of the best fitting straight line for the baleen plate is $y=3.40 x+44.77(x=$ num- 


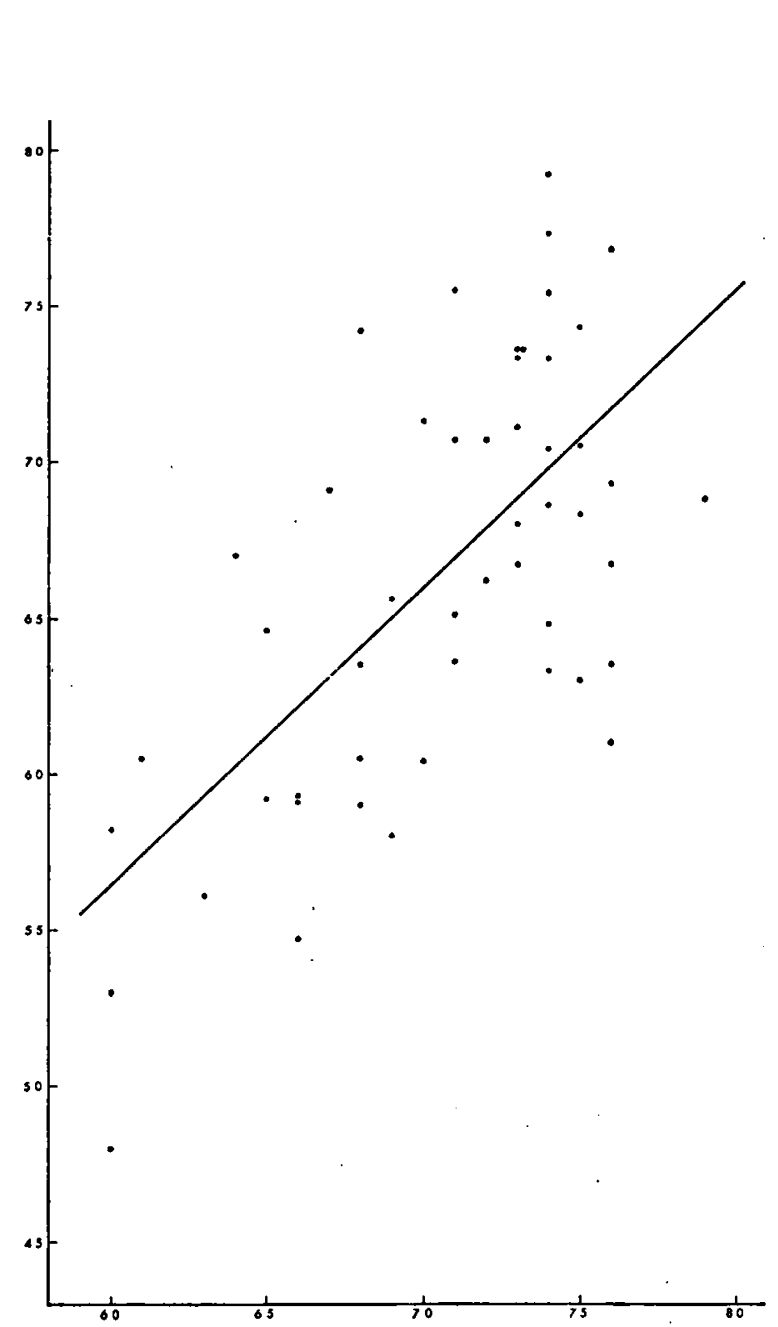

Fig. 5. Length of the outer baleen plate compared with the length of the animal. Absciss: length of the animal in feet. Ordinate: length of the baleen plate in $\mathrm{cm}$.

ber of "growth periods" in the baleen plate, $y=$ length of the baleen plate in $\mathrm{cm}$ ). This line differs significantly from the horizontal line $(v=50, t=$ 4.9, $\mathrm{P}<0.05$ ) (fig. 7).

For the ear plug the equation is $y=5.95 x+$ 6.51 ( $x=$ number of "growth periods" in the ear plug, $y=$ length of the ear plug in $\mathrm{cm}$ ). This line also differs significantly from the horizontal line $(v=$ $49, \mathrm{t}=9.1, \mathrm{P}<0.05$ ) (fig. 8).

\section{B. Length of the "Growth PERIODS" in the baleEN PLATE AND THE EAR PLUG}

The mean lengths of the "growth periods" in the records of the ear plugs vary from $40 \mathrm{~mm}$ to $111 \mathrm{~mm}$

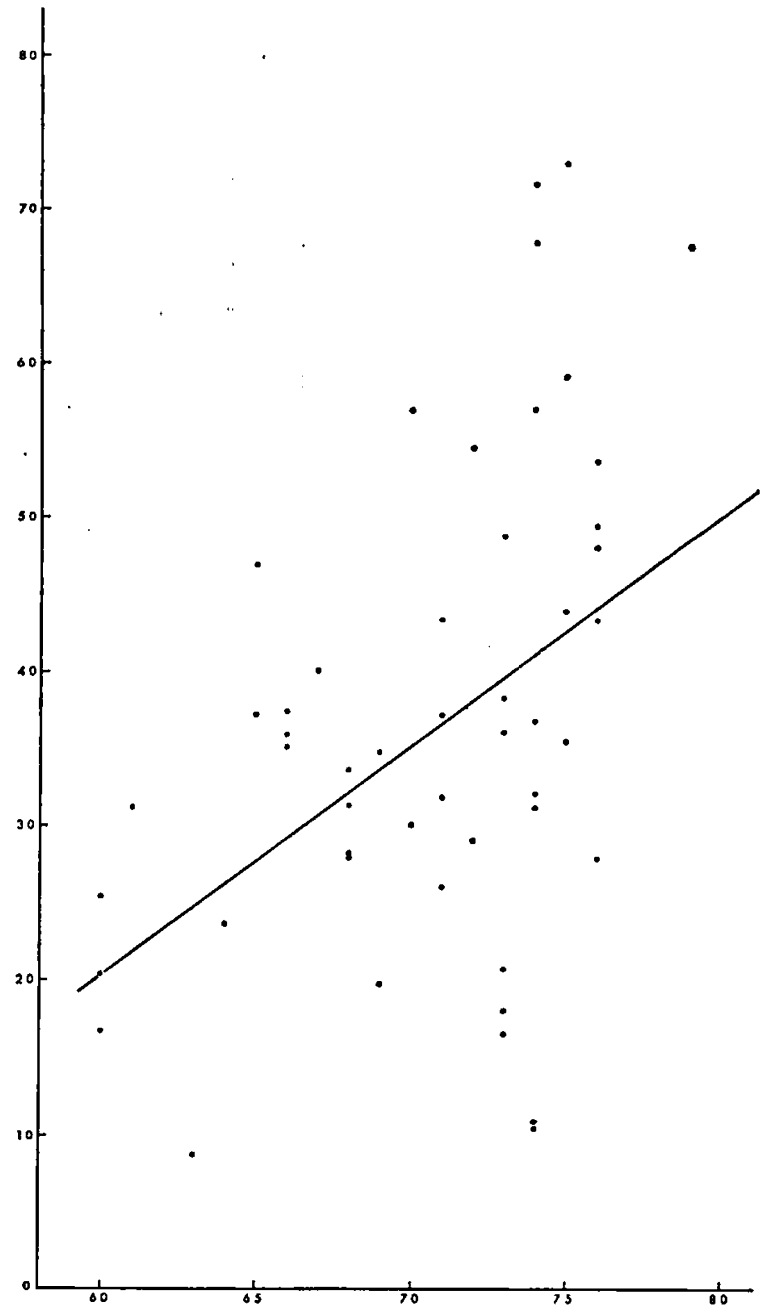

Fig. 6. Length of the ear plug compared with the length of the animal. Absciss: length of the animal in feet. Ordinate: length of the ear plug in $\mathrm{cm}$ (enlargement $8.5 \mathrm{x}$ ).

$(8.5 \times$ enlarged). In the baleen records the lengths of the "growth periods" vary from $94 \mathrm{~mm}$ to $179 \mathrm{~mm}$. In each individual fin whale the length of the "growth periods" in the record of the ear plug does not show a greater variation than the length of the "growth periods" in the record of the baleen plate does. However, the variation in length of the "growth periods" in the records of the ear plugs of various individuals is much greater than in the records of the baleen plates. This is shown in the figs. 9 and 10. On the ordinate the numbers of "growth periods" are given, on the absciss the lengths of the "growth periods", divided into groups per $5 \mathrm{~mm}$-increase in length per group. The mean length of the "growth periods" in 


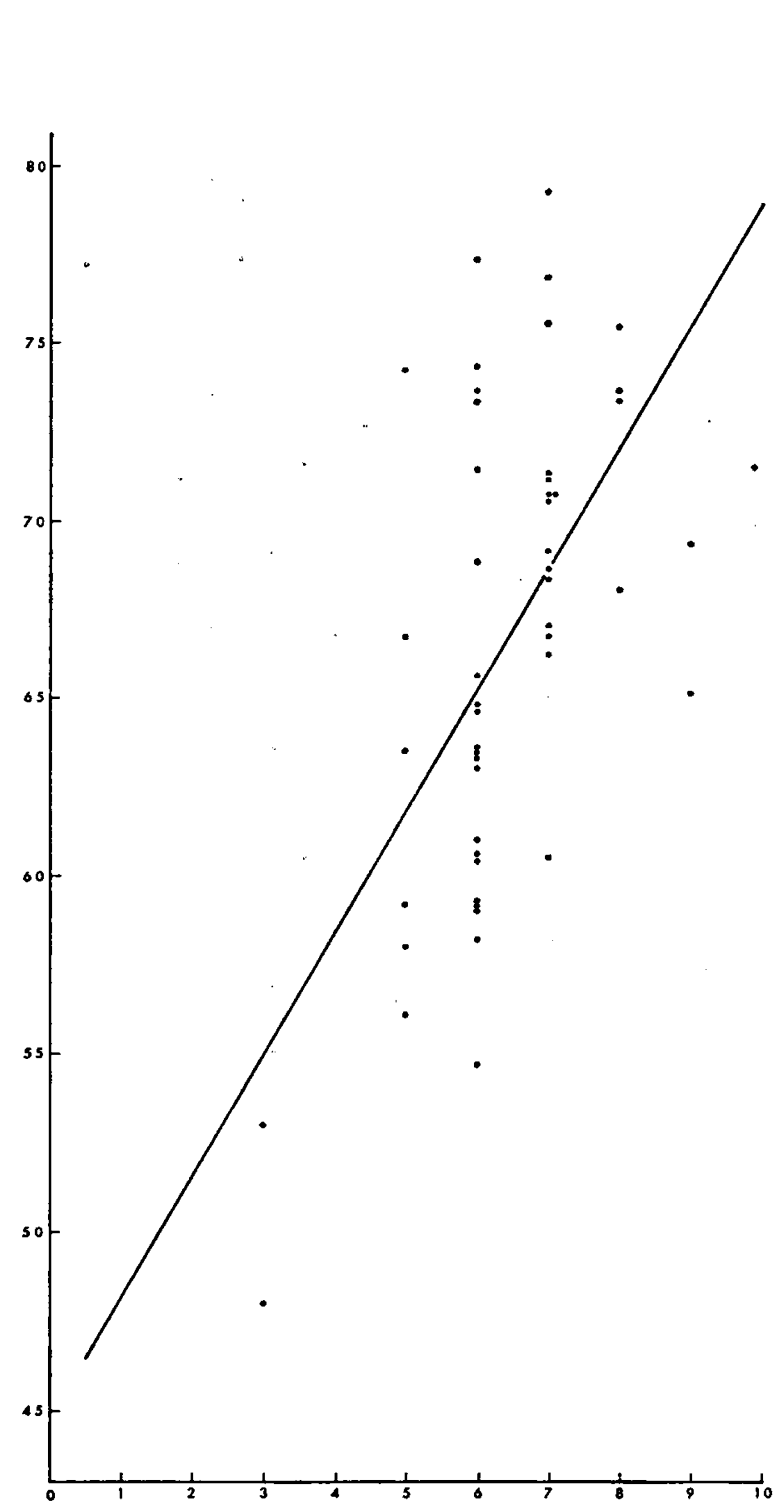

Fig. 7. Number of "growth periods" in the total baleen plate compared with the length of the baleen plate. Absciss: number of growth periods". Ordinate: length of the baleen plate in $\mathrm{cm}$.

the ear plug of all individuals taken together, is $63 \mathrm{~mm}$ (8.5 times linear enlargement). The mean length of the "growth periods" in the baleen plate of all individuals taken together, is $119 \mathrm{~mm}$.

It has been shown that there is a relation between the length of the "growth periods" in a baleen record and the number of periods in the outer baleen plate (Van Utrecht-Cock, 1966). "These differences may be caused by individual differences in the rate of growth of the baleen plate. In animals with three

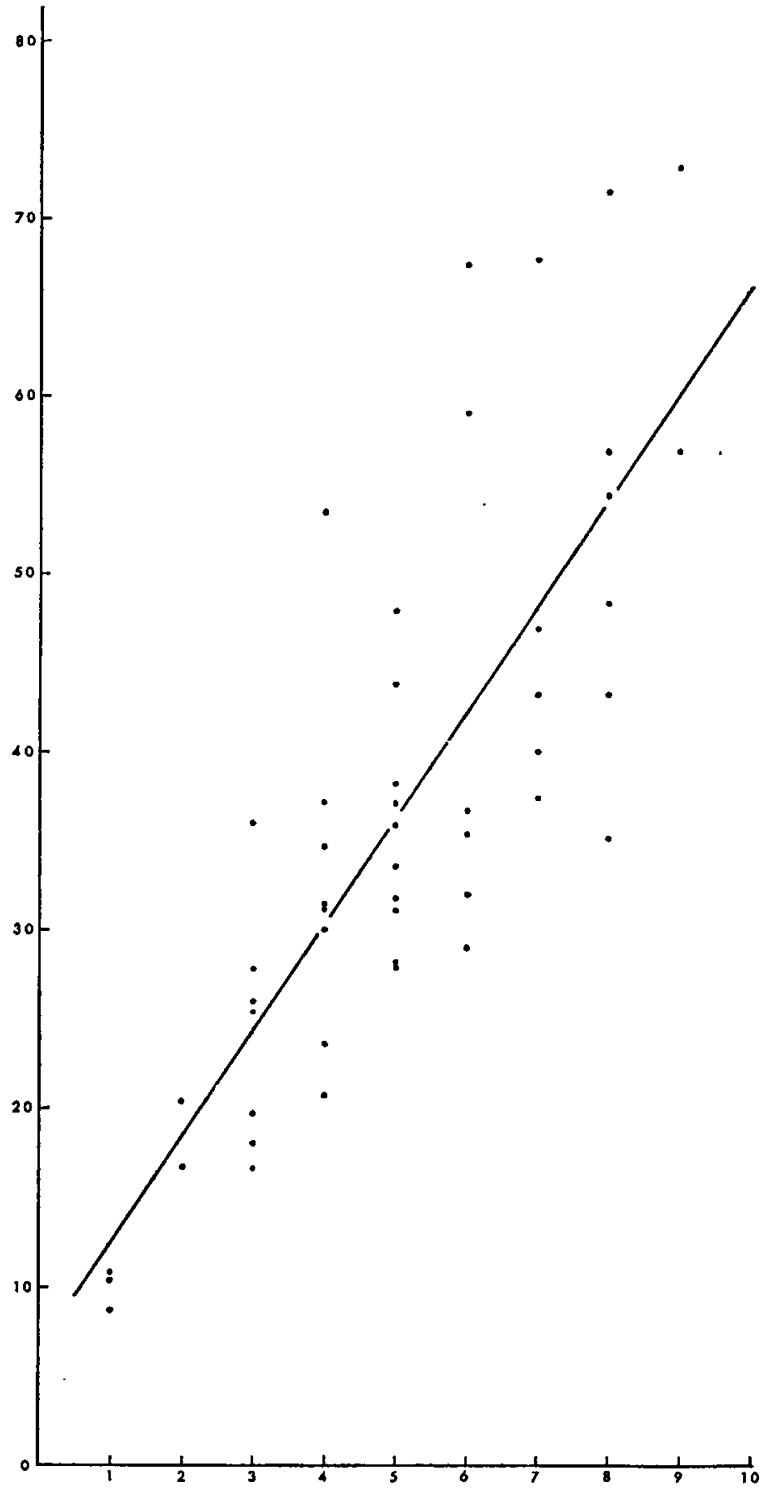

Fig. 8. Number of "growth periods" in the ear plug compared with the length of the ear plug. Absciss: number of "growth periods". Ordinate: length of the ear plug in $\mathrm{cm}$ (enlargement $8.5 \mathrm{x}$ ).

complete "growth periods" in the outer baleen plate the mean length of the "growth periods" is significantly longer than the mean length of the "growth periods" of an animal with seven periods in the record of the outer baleen plate". This was also evident in the records of baleen plates used here. The equation of the best fitting straight line (fig. 11) is $\mathrm{y}=-12.02 \mathrm{x}+$ 198.90 ( $x=$ number of periods in the outer baleen plate, $y=$ length of the "growth periods" in the outer baleen plate). This line differs significantly from the 


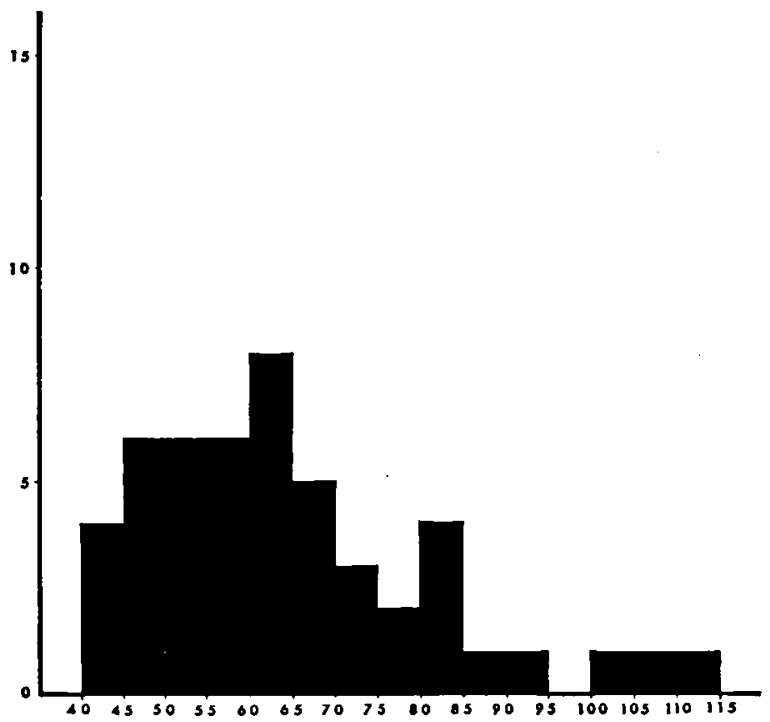

Fig. 9. Frequency of length groups of "growth periods" in the ear plug. Absciss: length of the "growth periods", divided in groups per $5 \mathrm{~mm}$ increase (enlargement $8.5 \mathrm{x}$ ). Ordinate: number of "growth periods".

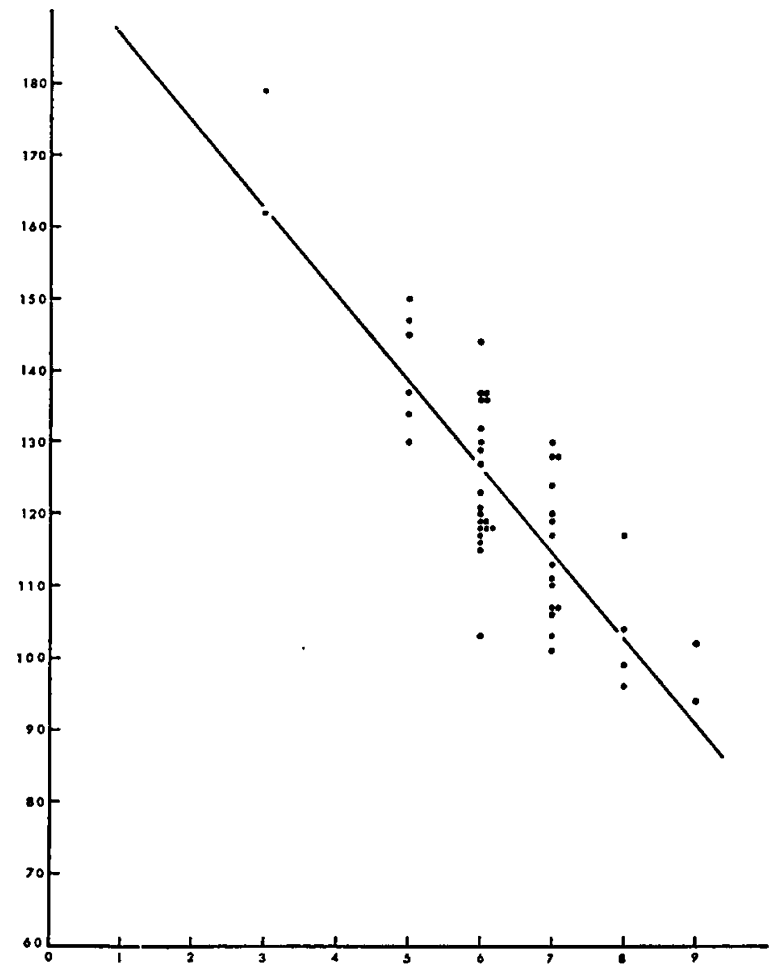

Fig. 11. Number of "growth periods" in the outer baleen plate compared with the length of these "growth periods". Absciss: number of "growth periods". Ordinate: length of the "growth periods".

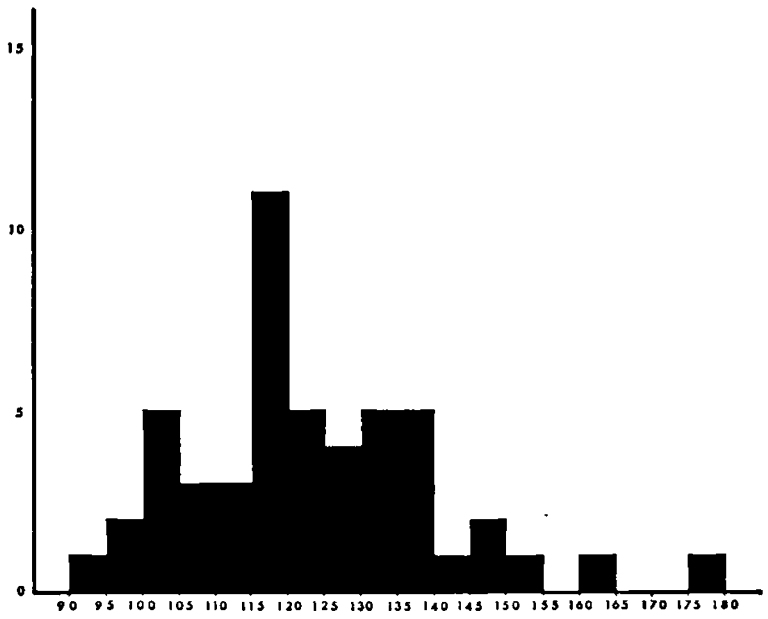

Fig. 10. Frequency of length groups of "growth periods" in the outer baleen plate. Absciss: length of "growth periods", divided in groups per $5 \mathrm{~mm}$ increase. Ordinate: number of "growth periods".

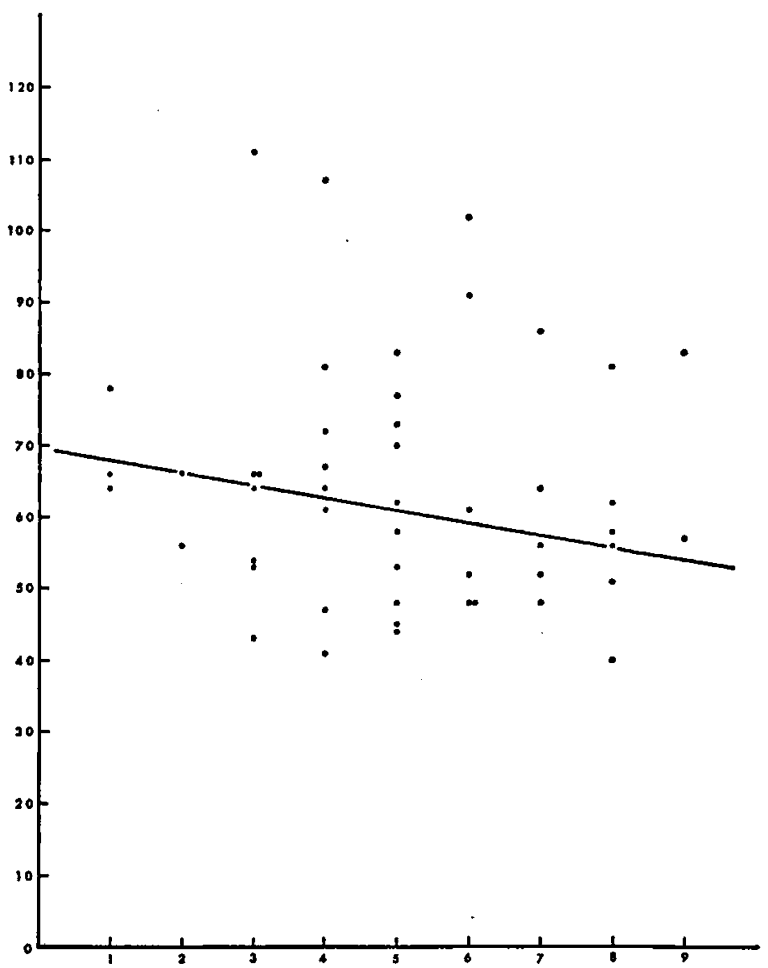

Fig. 12. Number of "growth periods" in the ear plug compared with the length of these "growth periods". Absciss: number of "growth periods". Ordinate: length of the "growth periods". 
horizontal straight line $(v=50, \mathrm{t}=3.3, \mathrm{P}<0.05)$.

In the ear plugs no relation is found between the number of "growth periods" and the length of these periods. The equation for the best fitting straight line is $y=1.78 x+69.94(x=$ number of periods in the ear plug, $y=$ length of the "growth periods" in the ear plug) (fig. 12). This line does not differ significantly from the horizontal line $(v=49, t=1.03$, $P>0.05$ ).

A possible explanation for the differences between the baleen plate and the ear plug may be found in the differences in the direction in which material is added to the ear plug and to the baleen plate. In the ear plug the addition of new cell material to the plug is in the same direction as the plug grows, perpendicular from the meatal surface of the glove finger in distal direction and the cells in the various layers are also flattened in this direction. To the sides of the glove finger the thickness of the epithelium rapidly decreases and obviously also the amount of cell material added to the plug here, because the lateral parts of the plug rapidly become thinner (see e.g. Ichihara, 1959). Moreover, here the addition is also in the direction of growth of the ear plug, although the amounts of cell material added are very small as compared with those at the top of the glove finger. This can be seen in a bisected ear plug, because to the sides of the core of the plug the light and dark layers taper out and are hard to distinguish here. Is is clear that the increase in length is the most important as is shown by Ichihara (1959). In the ear plug the growth in length exceeds far the increase in the direction perpendicular to the long axis of the plug. His fig. 8 shows clearly the small changes in size perpendicular to the long axis of the plug, which take place during the life of the animal, though there are of course individual variations.

In the "root" of the baleen plate the situation is different (see Van Utrecht, 1966; p. 22; fig. 25). Here the general direction of growth is also in the direction of the long axis of the plate, thus perpendicular to the surface of the epithelium in which the "root" is embedded and by which it is formed. The direction in which the cells of the epithelium move to form the cortical layer of the baleen plate, from which the sculpture is used in age determination, however, is quite different. Besides a general movement of cells parallel to the direction of the long axis of the baleen plate there is a movement of cells in a direction diverging about $30^{\circ}$ to $50^{\circ}$ from the former. This is sure to have its effect on the lengths of the "growth periods" in the baleen plates and the ear plugs. It is to be expected that the variation in the length of the "growth periods" in the records of the ear plugs will be greater because the direction of growth of the ear plug is only longitudinal and all cell material is added to the proximal end of the core. It is clear that variation in amount of cell material added in this direction, will result in greater variations in the lengths of the "growth periods" in the records of the ear plugs of the various animals. In the baleen record it is to be expected that the variations in lengths of the "growth periods" is smaller in the various individuals as the direction of the addition is under an angle with the long axis.

In the material used for the present examination no difference was found contrary to earlier results (Van Utrecht-Cock, 1966) in the relation between the age of the animal and the length of the "growth periods" in the baleen plate.

The equation for the best fitting straight line is $y=-0.09 x+121.26(x=$ number of corpora in the ovaries, $y=$ length of the "growth periods" in the baleen plate) (fig. 13). This line does not differ significantly from the horizontal line $(v=46, \mathrm{t}=$ $0.44, \mathrm{P}>0.05$ ).

The reason for this difference may be that the number of animals from which the baleen plates and ear plugs etc. were used in this comparison, is too small to reach a representative composition for the various age groups.

For the ear plugs there was also no relation between the age of the animal and the length of the "growth periods" in these ear plugs. The equation for the best fitting straight line is $y=0.20 \mathrm{x}+$ 61.30 ( $x=$ number of corpora in the ovaries, $y=$ length of the "growth periods" in the ear plug) (fig. 14). This line does not differ significantly from the horizontal line $(v=45, \mathrm{t}=0.80, \mathrm{P}>0.05)$.

Whether there will be the same relation between the age of the animal and the length of the "growth periods" in the baleen plate, and between the age of the animal and the length of the "growth periods" in the ear plug or whether there will be a difference, is uncertain. The material used for this comparison is too small.

As well in the baleen plates as also in the ear plugs no direct relation was found between the age of the animal, based on the number of corpora in the ovaries, and the number of "growth periods" present. For the baleen plate the equation of the best fitting straight line is $y=1.34 x+3.75(x=$ number of "growth periods" in the baleen plate, $y=$ number of corpora in the ovaries) (fig. 15). This line does not differ 


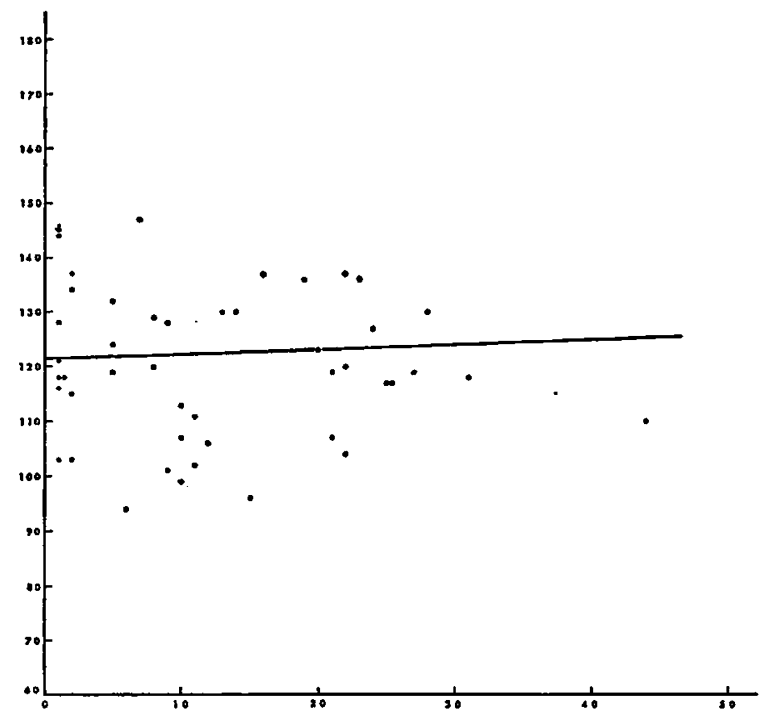

Fig. 13. Length of the "growth periods" in the outer baleen plate compared with the age of the animal. Absciss: number of corpora in the ovaries. Ordinate: length of the "growth periods".

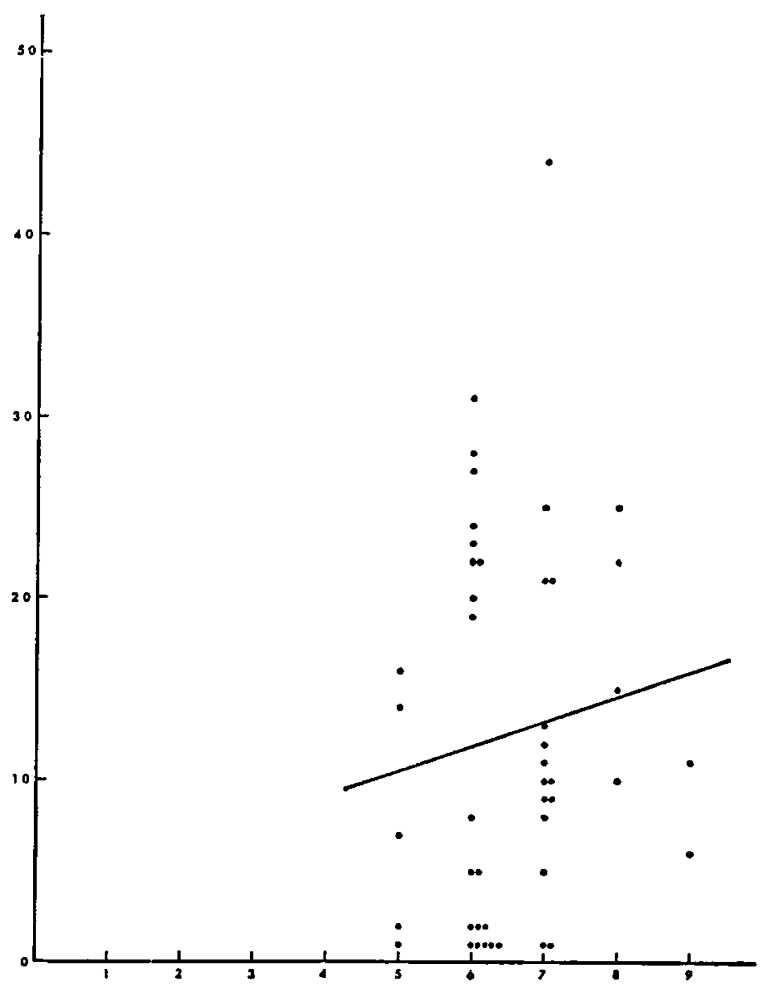

Fig. 15. Number of "growth periods" in the total baleen plate compared with the age of the animal. Absciss: number of corpora in the ovaries. Ordinate: number of "growth periods".

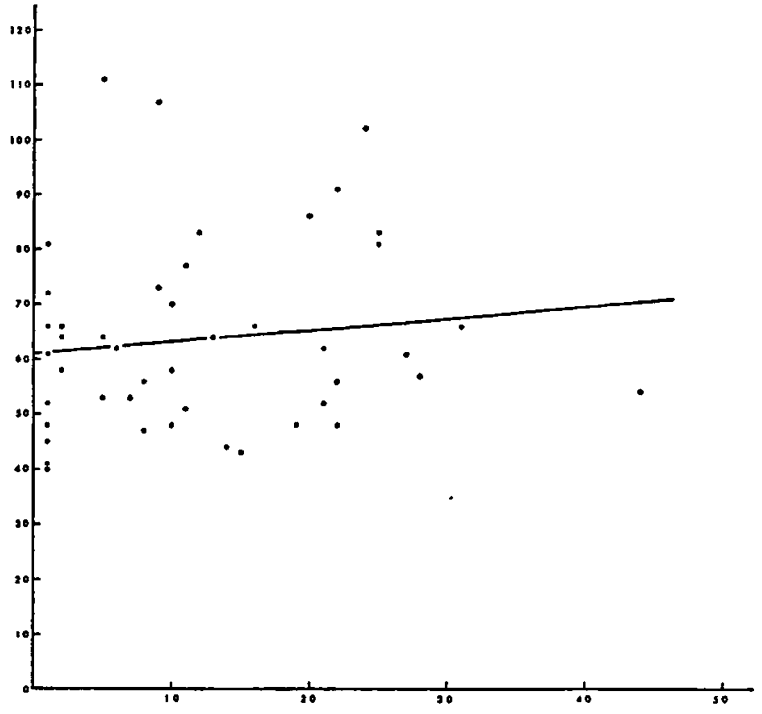

Fig. 14. Length of the "growth periods" in the ear plug compared with the age of the animal. Absciss: number of corpora in the ovaries. Ordinate: length of the "growth periods".

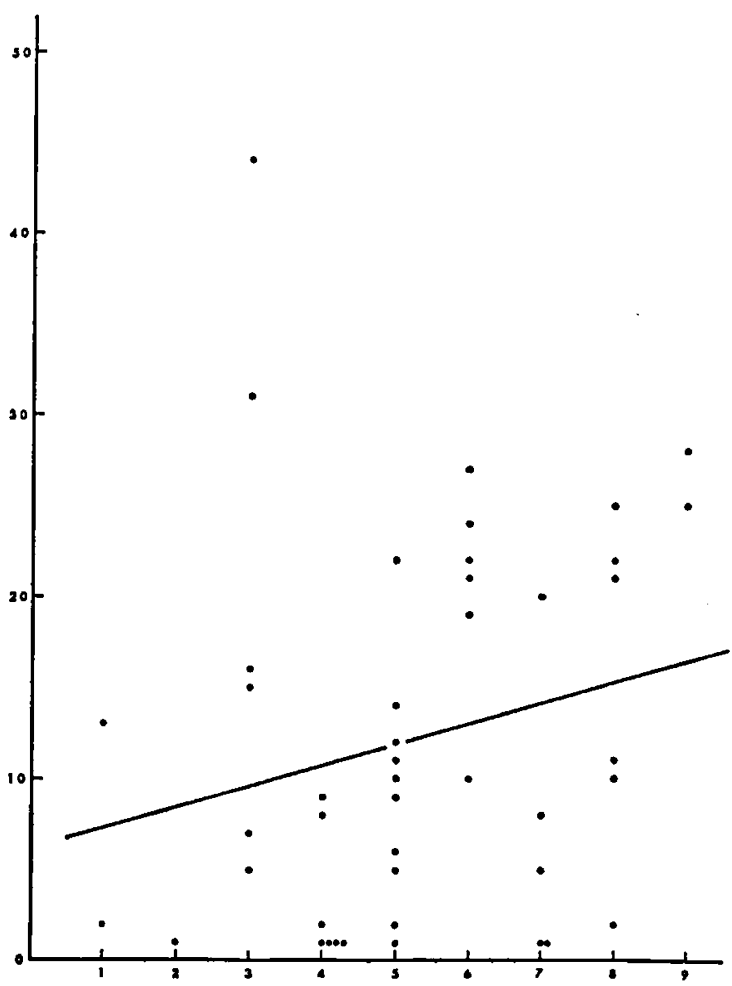

Fig. 16. Number of "growth periods" in the ear plug compared with the age of the animal. Absciss: number of corpora in the ovaries. Ordinate: number of "growth periods". 
significantly from the horizontal line $(\nu=46, t=$ $0.84, P>0.05)$. For the ear plug the equation for the best fitting straight line is $\mathrm{y}=1.16 \mathrm{x}+6.15$ ( $x=$ number of "growth periods" in the ear plug, $y=$ number of corpora in the ovaries) (fig. 16). This line also does not differ significantly from the horizontal line $(v=45, t=1.55, \mathrm{P}>0.05)$.

In previous work (Van Utrecht-Cock, 1966) it has been shown that the baleen plate can only grow to a certain length. When this length is reached wear at the tip compensates further growth. Therefore, as a mean, about 5-7 "growth periods" are then present in the total baleen plate (part of the baleen plate embedded in the gum + outer baleen plate). The longest baleen plate of a female fin whale we ever had, showed 10 "growth periods".

As is shown above, there was also no direct relation between the age of the animal and the number of "growth periods" present in the ear plug. The maximum number of "growth periods" found in the ear plugs is 9. The calculated age of these two animals is 28.4 and 26 years respectively. In all other animals, even the older ones, the number of "growth periods" is consistenly lower (see table II). This is a strong indication that the increase in length of the ear plug is obstructed in some way or other at a certain moment during the life of the animal. The moment at which this obstruction influences further outgrowth of the ear plug shows great individual variations.

From table II it is evident that there is a considerable discrepancy between the number of "growth periods" in the ear plugs and in the baleen plates (see also figs. $2 \mathrm{~d}$ and $2 \mathrm{e}$ ).

In $21 \%$ of the cases the number of "growth periods" in the baleen plate and in the ear plug was the same. In $17 \%$ of the animals examined the number of "growth periods" in the baleen plate was smaller ( 1 to 3 periods) than it is in the ear plug. In $62 \%$ of the animals the number of "growth periods" was greater in the baleen plate ( 1 to 6 periods) than it is in the ear plug.

\section{CONCLUSIONS}

This investigation shows that in each individual the record of the ear plug is completely comparable to the record of the baleen plate. In both records the sequence of peaks and hollows is the same. This may be reasonably explained by the assumption that factors influencing the mitotic activity in the epidermal tissue which forms the baleen plate, similarly influence the epidermal tissue forming the ear plug.
The record of the baleen plate can be divided into "growth periods" (representing about 12 months each), based on the regular repetition of a series of peaks and hollows arranged in a sequence which is typical for each individual (Van Utrecht-Cock, 1966). The peaks and hollows in each "growth period" represent the variations in the rate of addition of material to the baleen plate and are instantaneous depositions (Van Utrecht, 1966).

In each individual the record of the ear plug can also be divided into "growth periods" showing the same repeated sequence of peaks and hollows as present in the "growth periods" in the record of the baleen plate. So the "growth periods" in the records of the ear plugs are comparable to the "growth periods" in the records of the baleen plates. The layers in the ear plug, represented as peaks and hollows in the record, are comparable to the "relief" at the surface of the baleen plate, which is represented as peaks and hollows in the record of the baleen plate. This shows that counting of the layers in the ear plug for age determination has no sense. The layers are not deposited as one or two layers per year, but are instantaneous depositions related to or induced by changes in the physiology of the animal (e.g. an ovulation, migration, food, pregnancy, lactation, etc.). This means that more layers per year are formed, and that the number of layers formed per year shows individual variations. This is confirmed by the great resemblance of the record of the ear plug and baleen plate in each individual. These facts are completely contradictory to the views given in former studies, which have been summarized by Mackintosh (1965, p. 100-104).

In $79 \%$ of the animals examined the number of "growth periods" in the ear plug does not correspond with the number of "growth periods" in the baleen plate. This is in agreement with the fact that animals which have exceptionally long baleen plates can have very short ear plugs (e.g. reg.no. 646, length of the ear plug $10.4 \mathrm{~cm}$ (enlargement $8.5 \mathrm{x}$ ), length of the baleen plate $79.2 \mathrm{~cm}$, age calculated from the ovaries 16.4 years), while also the reverse situation occurs (e.g. reg.no. 747, length of the ear plug $72.8 \mathrm{~cm}$ (enlargement $8.5 \mathrm{x}$ ), length of the baleen plate $68.3 \mathrm{~cm}$, age calculated from the ovaries 26.0 years).

From the material examined it is evident that in general in the record of the ear plug a smaller number of "growth periods" is found than in the record of the complete baleen plate (outer baleen plate + part of the plate embedded in the gum). This is in our opinion a clear indication that the usefulness of the ear plugs in age determination is uncertain. This 
baleEN PLates aND EAR PLUGS

Table II Comparison of both methods of age determination

\begin{tabular}{|c|c|c|c|c|c|}
\hline number & $\begin{array}{c}\text { number of } \\
\text { periods in } \\
\text { ear plug }\end{array}$ & $\begin{array}{l}\text { mean length } \\
\text { period ear } \\
\left.\text { plug }(\mathrm{mm})^{1}\right)\end{array}$ & $\begin{array}{l}\text { number of } \\
\text { periods in } \\
\text { baleen plate }\end{array}$ & $\begin{array}{l}\text { mean length } \\
\text { period baleen } \\
(\mathrm{mm})\end{array}$ & $\begin{array}{l}\text { age on ovaries } \\
\text { in year }\end{array}$ \\
\hline $\begin{array}{r}179 \\
180 \\
211 \\
212 \\
227 \\
235 \\
375 \\
378 \\
380 \\
406 \\
417 \\
418 \\
421 \\
447 \\
480 \\
481 \\
574 \\
606 \\
608 \\
624 \\
646 \\
652 \\
653 \\
668 \\
670 \\
690 \\
702 \\
722 \\
726 \\
747 \\
748 \\
749 \\
759 \\
761 \\
817 \\
818 \\
824 \\
852 \\
855 \\
869 \\
870 \\
873 \\
928 \\
929 \\
1098 \\
1136\end{array}$ & $\begin{array}{l}5 \\
4 \\
5 \\
1 \\
5 \\
4 \\
8 \\
4 \\
3 \\
1 \\
5 \\
5 \\
7 \\
3 \\
9 \\
7 \\
2 \\
7 \\
4 \\
8 \\
1 \\
2 \\
4 \\
6 \\
6 \\
3 \\
4 \\
7 \\
5 \\
9 \\
3 \\
4 \\
6 \\
5 \\
6 \\
3 \\
8 \\
4 \\
8 \\
8 \\
7 \\
5 \\
3 \\
6 \\
5\end{array}$ & $\begin{array}{r}48 \\
72 \\
45 \\
78 \\
58 \\
81 \\
62 \\
61 \\
66 \\
66 \\
73 \\
83 \\
64 \\
111 \\
57 \\
52 \\
66 \\
56 \\
107 \\
56 \\
64 \\
56 \\
47 \\
91 \\
48 \\
53 \\
64 \\
48 \\
53 \\
83 \\
66 \\
67 \\
61 \\
62 \\
48 \\
52\end{array}$ & $\begin{array}{l}6 \\
6 \\
6 \\
5 \\
6 \\
5 \\
7 \\
6 \\
5 \\
6 \\
7 \\
7 \\
6 \\
7 \\
6 \\
7 \\
6 \\
7 \\
7 \\
8 \\
7 \\
3 \\
6 \\
6 \\
6 \\
5 \\
5 \\
6 \\
6 \\
6 \\
7 \\
6 \\
6 \\
6 \\
9 \\
9 \\
7 \\
3 \\
8 \\
7 \\
6 \\
6 \\
7 \\
6 \\
\end{array}$ & 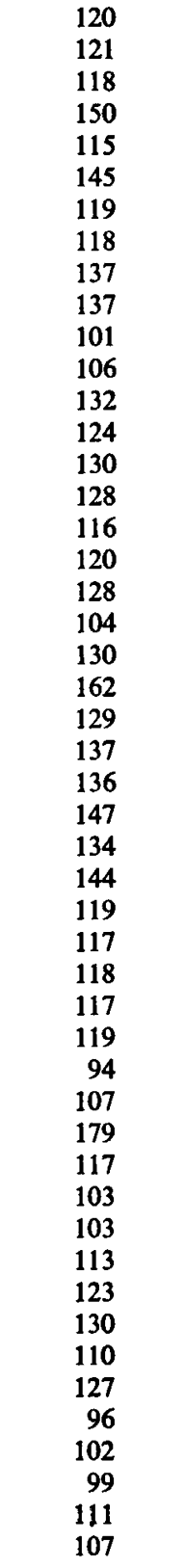 & $\begin{array}{r}23.6 \\
6.8 \\
6.8 \\
\text { max. } \\
7.6 \\
6.8 \\
22.8 \\
6.8 \\
18.8 \\
7.6 \\
13.2 \\
15.6 \\
10.0 \\
10.0 \\
28.4 \\
6.8 \\
6.8 \\
12.4 \\
13.2 \\
23.6 \\
16.4 \\
\max .6 \\
12.4 \\
23.6 \\
21.2 \\
11.6 \\
7.6 \\
6.8 \\
10.0 \\
26.0 \\
30.8 \\
\max .6 \\
27.6 \\
10.8 \\
14.0 \\
\max .6 \\
26.0 \\
6.8 \\
7.6 \\
14.0 \\
22.0 \\
17.2 \\
41.2 \\
25.2 \\
18.0 \\
14.8 \\
14.0 \\
14.8\end{array}$ \\
\hline
\end{tabular}

1) linear enlargement $8.5 \times$ 
uncertainty does not exist in the age determination based both on baleen plates and the results of the examination of the ovaries, though this method of age determination is only useful in female fin whales.

Of the baleen plate it is known that wear at the tip is the cause that only part of the plate as it has been formed during the life of the animal is available (Ruud, 1940, 1945; Van Utrecht-Cock, 1966). From the fact that in general the number of "growth periods" in the records of the ear plugs is even smaller than in the records of the baleen plates it must be concluded, contrary to what is generally supposed, that here also only a part of the material formed during the life of the whale is visible as layers (peaks and hollows in the record). At the tip the layers which form the core of the ear plug have been pressed together so strongly as to form a mass in which the separate layers are no longer visible.

In the records of the ear plugs no indications are found that older "growth periods", formed at a younger age of the animal, are shorter, as is clear from table III. Therefore it must be concluded that compression of the layers, at the tip of the core, is not gradual but occurs suddenly.

From all data produced is must be concluded that, although the ear plug is completely protected in the external meatus and not subject to wear, and its growth is influenced by the same factors as found for the baleen plate, the age determination based both on baleen plates and ovaries gives far more reliable results. A limitation is that this method gives the best results for female fin whales, but the same is true for the ear plugs.

\section{SUMMARY}

1. From 54 female fin whales chosen at random from a greater number of animals from which data and material were collected during the Antarctic whaling season 1962/1963, records have been made of the baleen plates and the ear plugs.

For the records the complete baleen plates including the part of the plates embedded in the gum are used. All ear plugs used for this study were complete and undamaged.

2. According to their ovaries and baleen records 50 animals were sexually mature, 4 animals were sexually immature.

3. In each individual the record of the complete baleen plate is entirely comparable to the record of the ear plug, in its general trend and in the sequence of peaks and hollows. Also the regular cyclic repeti-
Table III "Growth periods" in the ear plug, per period the mean length

\begin{tabular}{|c|c|c|c|c|c|c|c|c|c|}
\hline number of animals & I & II & III & IV & V & VI & VII & VII & IX \\
\hline 4 & 69 & & & & & & & & \\
2 & 53 & 56 & & & & & & & \\
8 & 62 & 68 & 72 & & & & & & \\
8 & 70 & 67 & 73 & 71 & & & & & \\
10 & 63 & 64 & 63 & 61 & 59 & & & & \\
5 & 59 & 57 & 60 & 63 & 58 & 57 & & & \\
6 & 54 & 57 & 61 & 56 & 58 & 58 & 59 & & \\
5 & 69 & 72 & 68 & 67 & 67 & 65 & 65 & 62 & \\
1 & 66 & 58 & 51 & 62 & 59 & 54 & 49 & 64 & 48 \\
\hline total mean & 63 & 64 & 66 & 64 & 60 & 60 & 61 & 63 & 48 \\
\hline
\end{tabular}

tion found in the records of the baleen plates is present in the records of the ear plugs. The comparison of the records of baleen plates with those of ear plugs is only possible when it starts with the last formed part, forming the basis of the core of the plug and the first part of the cortex of the baleen plate deep in the gum, because these represent both the same moment in the life of the animal which is exactly known, viz. the moment in which the growth stopped due to the death of the animal.

4. In the records of baleen plates and ear plugs of a number of immature animals the "double hump" or a part of it was found at the right hand side of both. In some of the animals an "ovulation peak" was present at the same time at the beginning (left hand end) in the record of the baleen plate and ear plug; in both in the same position with respect to the surrounding peaks and hollows. This is also true for the records of ear plugs and baleen plates of older females.

5. The records of the ear plugs can be divided into "growth periods" according to what is done in the records of the baleen plates. In each individual the division between the "growth periods" in the record of the ear plug are in the same position with respect to the sequence of the surrounding peaks and hollows as is found in the record of the complete baleen plate. In both records the cyclic repetition of peaks and hollows in the successive "growth periods" is clear.

6. In $21 \%$ of the animals examined the number of "growth periods" in the record of the ear plug is equal to the number present in the record of the baleen plate. In $17 \%$ of the animals examined the number of "growth periods" in the record of the baleen plate was lower ( 1 to 3 "growth periods") 
than was found in the record of the ear plug. In $62 \%$ of the animals examined the number of "growth periods" in the baleen plate was greater ( 1 to 6 periods) than was found in the ear plug.

7. Evidence was put foreward that the increase in length of the ear plug is obstructed after the animal has reached a certain age. This moment is not the same for all animals but is probably related to the various "constitution types" present in the catch. It is shown that in the distal end of the ear plug the length of the "growth periods" suddenly decreases, so only a certain maximum number of "growth periods" can be found. In the baleen plate the same situation exists due to wear at the tip of the plate. For these reasons the exact age of a fin whale can only be determined as long as wear at the tip of the baleen plate and compression of the distal layers of the ear plug does not occur.

8. From the evidence put foreward it is clear that age determination in fin whales by simply counting the layers present in the core of the ear plug is far too subjective and does not give reliable results. In our opinion best results for age determination in fin whales are obtained by counting the corpora present in the ovaries of females. When this number is divided by the mean ovulation rate $(1.25$, see Van Utrecht-Cock, 1966) and by adding 6 years (mean number of years before attainment of sexual maturity) the age of the animals calculated in this way is reasonably accurate.

\section{REFERENCES}

Bannister, J. L. and Baker, A. de C., 1967: Observations on food and feeding of baleen whales at Durban. Norsk Hvalfangst-Tidende, no. 4, p. 78.

Bullough, H. F., 1943: Cyclical changes in the skin of the mouse during the oestrus cycle. Journ. Endocrinol., Vol. 3, p. 280.

-, 1947: Epidermal thickness following oestrone injections in the mouse. Nature, Vol. 159 , no. 4029 , p. 101.

Bullovgh, W. S., 1946: Mitotic activity in the adult female mouse, Mus musculus L., a study of its relation to the oestrus cycle in normal and abnormal conditions. Phil. Trans. Soc. London, Sect. B., Vol. 231, p. 453.

-, 1962: The control of mitotic activity in adult mammalian tissues. Biol. Rev., Vol. 37, p. 307.

DAwBin, W. H., 1956: The migration of humpback whales which pass the New Zealand coast. Trans. Roy. Soc. N.Z., 84, p. 147.

ICHIHARA, T., 1959: Formation mechanism of ear plug in baleen whales in relation to glove finger. Sci. Rep. Wh. Res. Inst. Tokyo, no. 14, p. 107.

-, 1963: Photometric method for counting laminae in ear plug of baleen whale. Sci. Rep. Wh. Res. Inst. Tokyo, no. 17, p. 37 .

-, 1964: Prenatal development of ear plug in baleen whales. Sci. Rep. Wh. Res. Inst. Tokyo, no. 18, p. 29.

,- 1966: Criterion for determining age of fin whale with reference to ear plug and baleen plate. Sci. Rep. Wh. Res. Inst. Tokyo, no. 20, p. 17.

LAws, R. M., 1961: Reproduction, growth and age of southern fin whales. Discovery Reports, no. 31, p. 327.

Laws, R. M. and Purves, P. E., 1956: The ear plug of the Mysticeti as an indication of age with special reference to the North Atlantic fin whale (Balaenoptera physalus Linn.). Norsk Hvalfangst-Tidende, no. 8, p. 413.

Mackintosh, N. A., 1965: The stock of whales. Fishing News (Books) Ltd., London.

NaAktgeboren, C., Slijper, E. J., and Utrecht, W. L. vaN, 1960: Researches on the period of conception, duration of gestation and growth of the foetus in the fin whale, based on data from the International Whaling Statistics. Norsk Hvalfangst-Tidende, no,. 3, p. 113.
Orsumi, S., 1964: Examination on age determination of the fin whale. Sci. Rep. Wh. Res. Inst. Tokyo, no. 18, p. 49.

Punves, P. E., 1955: The wax plug in the external auditory meatus of the Mysticeti. Discovery Reports, Vol. 27, p. 293.

- , 1958: The use of the ear plug in age determination in whales. XVth Intern. Congr. Zool., Sect. 3, paper 35.

Purves, P. E. and Mountrord, M. D., 1959: Ear plug laminations in relation to the age composition of a population of fin whales (Balaenoptera physalus). Bull. Brit. Mus. (Nat. Hist.), Vol. 5, no. 6, p. 125.

Rice, D. W. and Wolman, A. A., 1967: The gray whale: Age, growth, reproduction, and the annual cycle. Sci. Comm. Intern. Whaling Comm., London.

RoE, H. S. J., 1967: The rate of the laminae formation in the ear plug of the fin whale. Norsk Hvalfangst-Tidende, no. 2 , p. 41 .

,- 1967a: Seasonal formation of lamina in the ear plug of the fin whale. Discovery Rep. 35, p. 1.

Ruod, J. T., 1940: The surface structure of the baleen plate as a possible clue to age in whales. Hvalrådets Skrifter, no. 23 , p. 1.

-, 1945: Further studies on the structure of the baleen plates and their application to age determination. Hvalrådets Skrifter, no. 29, p. 1.

- , 1958: The use of baleen plates in age determination of whales. XVth Intern. Congr. Zool., Sect. 3, paper 37.

Slijper, E. J., Utrecht, W. L. van and NaAkTgeboren, C., 1964: Remarks on the distribution and migration of whales, based on observations from Netherlands ships. Bijdr. Dierk., Afl. 34, p. 4.

UTREChT, W. L. vaN, 1966: On the growth of the baleen plate of the fin whale and the blue whale. Diss. Amsterdam, Bijdr. Dierk., Afl. 35, p. 3, (1965).

UTrecht-Cock, C. N. van, 1966: Age determination and reproduction of female fin whales, Balaenoptera physalus (Linnaeus, 1758) with special regard to baleen plates and ovaries. Diss. Amsterdam Bijdr. Dierk., Afl. 35, p. $39,(1965)$. 